
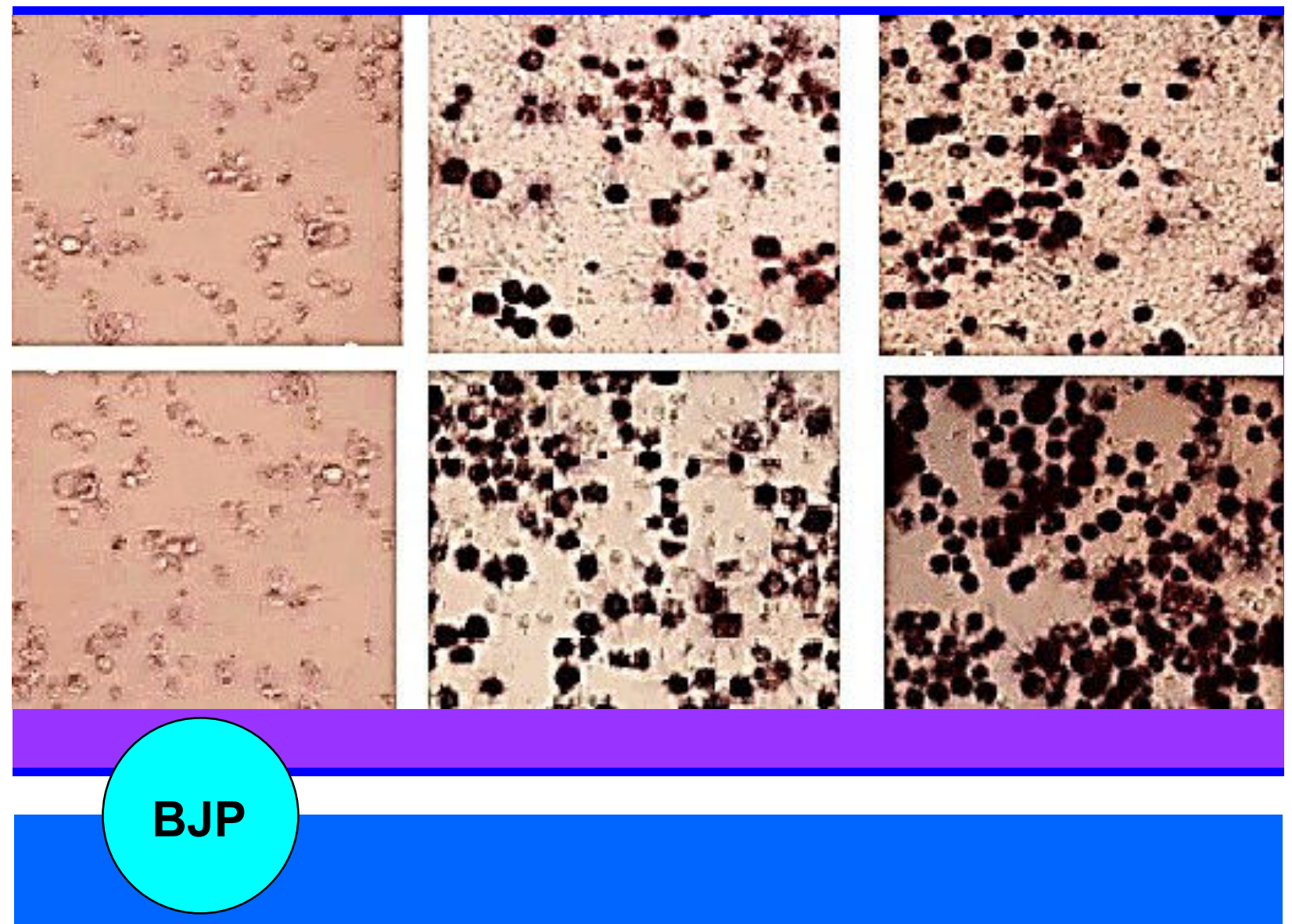

Bangladesh Journal of Pharmacology

Research Article

Alpha-naphthyl isothiocyanate triggering G2/M phase arrest and apoptosis in human brain malignant glioma U87MG cells via mitochondrial pathway 


\title{
Alpha-naphthyl isothiocyanate triggering G2/M phase arrest and apoptosis in human brain malignant glioma U87MG cells via mitochondrial pathway
}

\author{
Qiang Zhang, Yu-Ting Wang, Shi-Mei Jing, Jian-Yong Chang and Jin-Peng Wang \\ Department of Neurosurgery, Brain Hospital of Weifang People's Hospital, Weifang 261 041, China.
}

\begin{tabular}{|c|c|}
\hline Article Info & \\
\hline Received: & 3 December 2014 \\
\hline Accepted: & 3 February 2015 \\
\hline Available Online: & 6 March 2015 \\
\hline DOI: $10.3329 /$ bjp. & $0 \mathrm{i} 1.21096$ \\
\hline $\begin{array}{l}\text { Cite this article: } \\
\text { Zhang Q, Wang } \\
\text { JY, Wang JP. Alpl } \\
\text { cyanate triggering } \\
\text { and apoptosis in } \\
\text { nant glioma U87 } \\
\text { chondrial pathw } \\
\text { Pharmacol. 2015; } 1\end{array}$ & $\begin{array}{l}\text {, Jing SM, Chang } \\
\text {-naphthyl isothio- } \\
2 / \mathrm{M} \text { phase arrest } \\
\text { Iman brain malig- } \\
\mathrm{G} \text { cells via mito- } \\
\text { Bangladesh J } \\
\text { 183-90. }\end{array}$ \\
\hline
\end{tabular}

\begin{abstract}
Cancer protective effect of cruciferous vegetables is partly attributed to organic isothiocyanates (ITC) with an $-\mathrm{N}=\mathrm{C}=\mathrm{S}$ functional group. Elucidation of the mechanism by which ITCs impart protection against cancer has been the topic of intense research in the past few decades. In this study, we demonstrate that ANIT significantly decreased proliferation and viability of human brain malignant glioma U87MG cells in a dose-dependent manner. The cell cycle analysis showed that ANIT induced significantly G2/M arrest and sub-G1 phase (apoptotic population) in U87MG cells. CDK1 activity assay and Western blot analysis showed that there observed marked reduction in the CDK1/cyclin B activity and protein levels. Pretreatment with specific inhibitors of caspase-3 (Z-DEVE-FMK) and -9(Z-LEHD-FMK) significantly reduced caspase- 3 and -9 activity in U87MG cells. Western blot analysis and colorimetric assays also displayed that ANIT caused a timedependent increase in cytosolic cytochrome C, pro-caspase-9, Apaf-1, AIF, Endo $\mathrm{G}$ and the stimulatedcaspase- 9 and -3 activity.
\end{abstract}

\section{Introduction}

Glioblastoma is considered to be a death sentence to patients because of little response or resistance to the present therapeutic regimens, leading to short period of survival, usually less than a year between diagnosis and death (Eitel et al., 1999). Therefore, it is necessary to develop new medicine in order to improve the treatment efficacy. Recent studies have found that a large number of edible cruciferous plants, such as broccoli, cabbage and water celery, can reduce the risk of cancer. It has also been confirmed that the isothiocyanates compounds contained in these plants have anti-tumor ability (Pawlik et al., 2012; Singh et al., 2012).

Phenethyl and benzyl isothiocyanates inhibited carcinogenesis induced by carcinogens such as diethyl nitrosamine (DEN), dimethyl benzo(a)anthracene (DMBA) or benzo(a)pyrene (BP) (Wattenberg et al., 1987). The mechanism involved in the inhibition of carcinogenesis by ITCs is most likely due to the blocking of the activation of carcinogens through the inactivation of P450 enzymes and activation of Phase II enzymes (Wattenberg et al., 1987).

We hypothesized that resonance structure of naphthyl moiety would result in more effective anticancer agents based on the observation that in comparison to the phenyl and benzyl derivatives, naphthyl structure provides more electron donation. In addition, no previous study exists addressing whether the ANIT inhibits cell proliferation, promotes cell cycle arrest and induces apoptosis in human brain malignant glioma cells. The aim of the present study is to determine and explore ANIT-triggered G2/M phase arrest and cell death in U87MG cells via a mitochondria-dependent apoptotic signaling. 


\section{Materials and Methods}

\section{Reagents and chemicals}

Alpha-naphthylisothiocyanate (ANIT), [3-(4,5-dimethyl -thiazol-2-yl)-2,5-diphenyltetra-zolium bromide] (MTT), propidium iodide (PI), Triton X-100, RNase A, dimethylsulfoxide (DMSO) were purchased from Sigma Chemical Co. (USA). RPMI-1640 medium, fetal bovine serum (FBS), L-glutamine, penicillin-streptomycin and trypsin-EDTA were obtained from Gibco BRL/ Invitrogen Corp (USA). Caspase-9 inhibitor (ZLEHDFMK), caspase-8 inhibitor (Z-IETD-FMK) and caspase-3 inhibitor (Z-DEVD-FMK) were obtained from Invitrogen (R\&D Systems, Minneapolis, MN,USA)

Cells, culture method and cell morphology identification

U87MG cell lines (human brain malignant glioma) were purchased from the Food Industry Research and Development Institute (Hsinchu, Taiwan). Cells were plated onto $75 \mathrm{~cm}^{2}$ tissue culture flasks in RPMI-1640 medium supplemented with 10\% FBS, $100 \mathrm{U} / \mathrm{mL}$ penicillin, $100 \mu \mathrm{g} / \mathrm{mL}$ streptomycin and $2 \mathrm{mM} \mathrm{L}$ glutamine and grown at $37^{\circ} \mathrm{C}$ under a humidified $5 \%$ $\mathrm{CO}_{2}$ and $95 \%$ air at one atmosphere. U87MG cells of about $2 \times 10^{5}$ cells/well in a 12-well plate were treated with different concentrations $(0,10$, and $20 \mu \mathrm{M})$ ANIT and incubated for 24 and 48 hours. Cells were directly examined and were photographed under contrastphase microscope (Yang et al., 2009).

\section{MTT assay}

U87MG cells of about $1 \times 10^{4}$ cells/well in 96-well plates were treated with to $4,8,16,32$, and $64 \mu \mathrm{M}$ of ANIT and DMSO, $0.1 \%$ in media served as a vehicle control. After a 24 hours incubation, $100 \mu \mathrm{L}$ of $0.5 \mathrm{mg} / \mathrm{mL}$ MTT solution was added to each well, and the plate was incubated at $37^{\circ} \mathrm{C}$ for 3 hours. An aliquot of $100 \mu \mathrm{L}$ of $0.04 \mathrm{~N} \mathrm{HCl}$ in isopropanol was added and the absorbance at $570 \mathrm{~nm}$ was measured for each well with the cell survival ratio expressed as \% of control.

\section{Cell cycle distribution analysis}

The U87MG cells were seeded onto 12-well culture plates at $2 \times 10^{5}$ cells/well then incubated with $10 \mu \mathrm{M}$ of ANIT for 24 hours. The cells were harvested and washed by centrifugation. For cell cycle and apoptosis determination, cells were fixed by $70 \%$ ethanol in $-20^{\circ} \mathrm{C}$ overnight and then re-suspended in PBS containing 40 $\mu \mathrm{g} / \mathrm{mL}$ PI and $0.1 \mathrm{mg} / \mathrm{mL}$ RNase A and $0.1 \%$. Triton X100 in dark room for $30 \mathrm{~min}$. The cell cycle distribution and apoptotic nuclei were determined by flow cytometry (FACSCalibur ${ }^{\mathrm{TM}}$, USA).

\section{DAPI staining for apoptosis}

About $2 \times 10^{5}$ cells/well of U87MG cells in a 12-well plate were treated with 0 , and $10 \mu \mathrm{M}$ of ANIT and $0.1 \%$ DMSO as the control. Cells were incubated and grown for 24 hours. Cells were stained by 4'-6-diamidino-2phenylindole (DAPI) and were photographed under fluorescence microscopy.

\section{CDK1 kinase assay}

U87MG cells of about $1 \times 10^{7}$ density were suspended in a buffer containing a final volume of $0.2 \mathrm{~mL}, 50 \mathrm{mM}$ Tris-HC1(pH 7.5), $1 \mathrm{mM}$ phenylmethyl-sulfonyl fluoride, $50 \mathrm{pg} / \mathrm{mL}$ leupeptin, 2-mercapto-ethanol (10 $\mathrm{mM}), \mathrm{MgCl}_{2}(1 \mathrm{mM})$, EGTA (2 mM), dithio-threitol (0.5 $\mathrm{mM})$, Brij $(350.01 \%)$, b-glycerophosphate $(25 \mathrm{mM})$, and $\mathrm{NaCl}(0.5 \mathrm{M})$. Cell suspensions were sonicated and centrifuged for $30 \mathrm{~min}$. To determine the CDK1 kinase assay condition using MV Peptide, its absorbance was measured at $492 \mathrm{~nm}$ (Yang et al., 2004; Kuo et al., 2009). Assay was carried out according to the protocol of Medical and Biological Laboratories CDK1 kinase assay kit (MBL, Nagoya, Japan).

\section{Western blot}

U87MG cells of about $1 \times 10^{7}$ density in a 75-T flask were treated with $10 \mu \mathrm{M}$ of ANIT for $0,6,12,24$ and 48 hours. The examined cells were harvested and washed with cold PBS for detecting the changes of protein levels correlated with G2/M phase-modulated and apoptotic signaling. The total proteins were collected from ANIT-treated U87MG cells before the CDK1, cyclin B and cyclin A were detected and measured. The level of cytosolic fraction proteins such as cytochrome C, Apaf-1, pro-casepase9, AIF, and Endo G were determined and isolated according to the mitochondria/cytosol fractionation kit manufacturer's protocol (BioVision, Inc. Mountain View, CA, USA). U87MG cells after exposure to ANIT were harvested, disrupted and then centrifuged to isolate cytosolic fractions. The total or cytosolic protein $(40 \mu \mathrm{g})$ from each sample was resolved on $12 \%$ sodium dodecyl sulfate polyacrylamide gel electrophoresis (SDS-PAGE) and transferred to nitrocellulose membrane. The blot was soaked in blocking buffer $(5 \%$ non-fat dry mik/0.05\% Tween-20 in $20 \mathrm{mM}$ TBS at pH 7.6) at room temperature for 1 hour and then incubated with antiCDK1, anti-cyclin B, anti-cyclin A, anti-cytochrome c, anti-Apaf-1, antipro-casepase-9, anti-AIF, and antiEndo G antibodies (SantaCruz Biotechnology, Inc.) in blocking buffer at $4^{\circ} \mathrm{C}$ overnight. A secondary antibody horseradish peroxidase conjugate was added and detected by chemiluminescence and autoradiography using X-ray film. To ensure equal protein loading, each membrane was stripped and reprobed with anti $\beta$-actin antibody.

\section{Assays for caspase-3, -8 and -9 activities}

Caspase-3, -8 and -9 activities were assessed according to the manufacturer's instructions (Caspase colorimetric 
kit, R\&D-System Inc.). U87MG cells of about $1 \times 10^{7}$ density in a 75-T flask were pretreated with or without the selective inhibitors (Z-DEVE-FMK forcaspase-3, ZIETD-FMK for caspase-8 and Z-LEHD-FMK for caspase -8 ) and then treated with $10 \mu \mathrm{M}$ ANIT were incubated for 24 hours to detect caspase-3, -8 and -9 activities. Briefly, cells were harvested and lysed in $50 \mu \mathrm{L}$ lysis buffer containing $2 \mathrm{mM}$ DTT for $10 \mathrm{~min}$. After centrifugation, the supernatants containing $100 \mu \mathrm{g}$ proteins were incubated with caspase-3, -8 and -9 substrate in reaction buffer. Samples were incubated in a 96-well flat bottom micro-plate at $37^{\circ} \mathrm{C}$ for 1 hour. Levels of released pNA (Z-DEVEpNA, Z-IETD-pNA and ZLEHD-pNA for cas-pase-3, -8 and -9 , respectively) were measured with an ELISA reader (AnthosLabtec Instruments) at an absorbance of $405 \mathrm{~nm}$.

\section{Statistical analysis}

Student's t-test was used to analyze the differences between the ANIT-treated and control groups. All data were expressed as mean \pm SD from at least three independent experiments. $\mathrm{P}<0.05, \mathrm{p}<0.01$ and $\mathrm{p}<0.001$ were indicative of significant difference.

\section{Results}

The cell viability of ANIT on a human brain malignant glioma cell line U87MG was investigated by the MTT assay. The results shown in Figure $1 \mathrm{~A}$ indicated that ANIT significantly reduced the percentage of viable cells when compared to that of control cells. These effects were found to be in a dose-dependent manner.

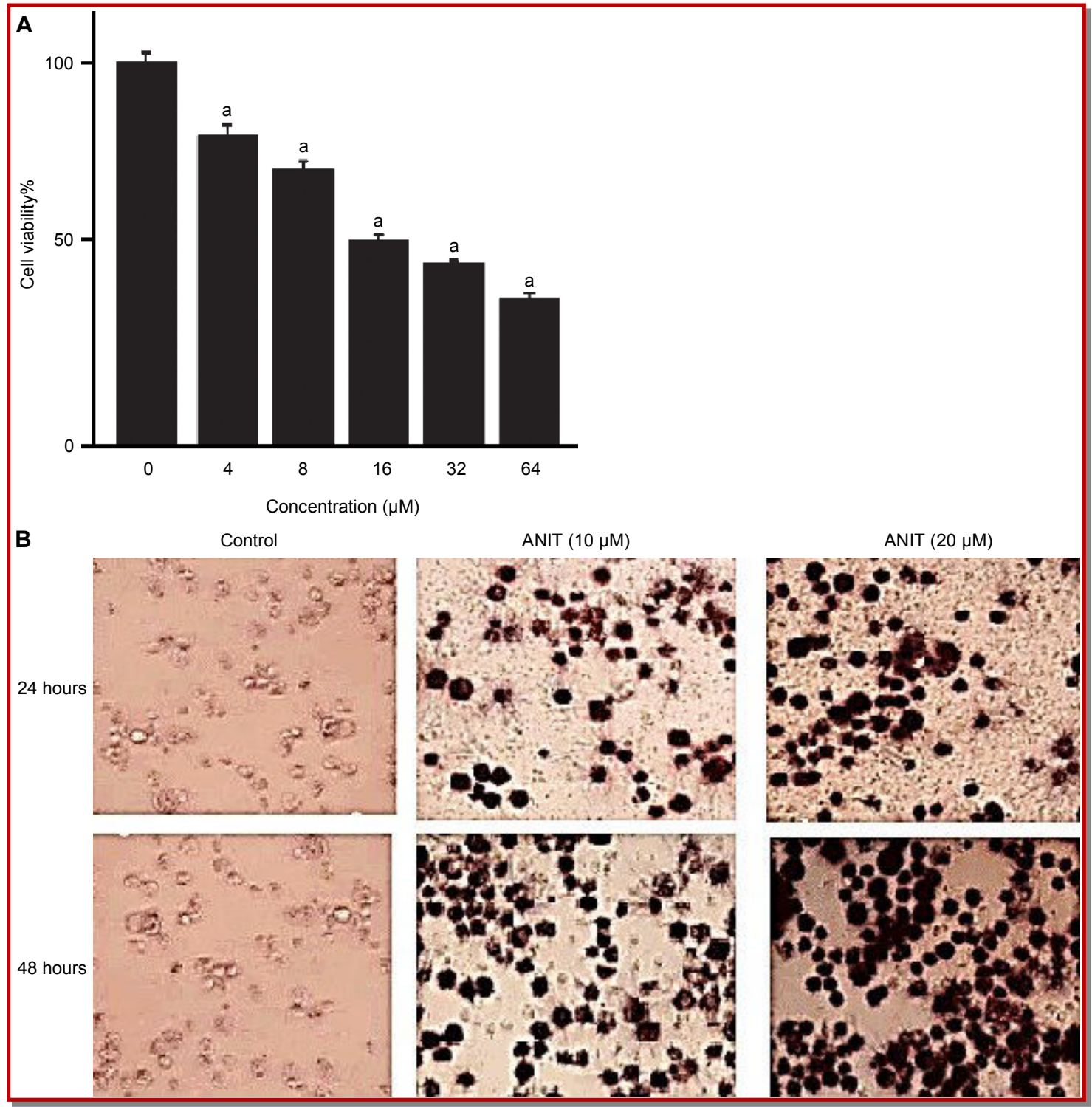

Figure 1: Effects of ANIT on cell viability (A) and morphology (B) of U87MG cells. Cells were cultured with 0, 4, 8, 16, 32 and 64 $\mu \mathrm{M}$ of ANIT for 24 hours 


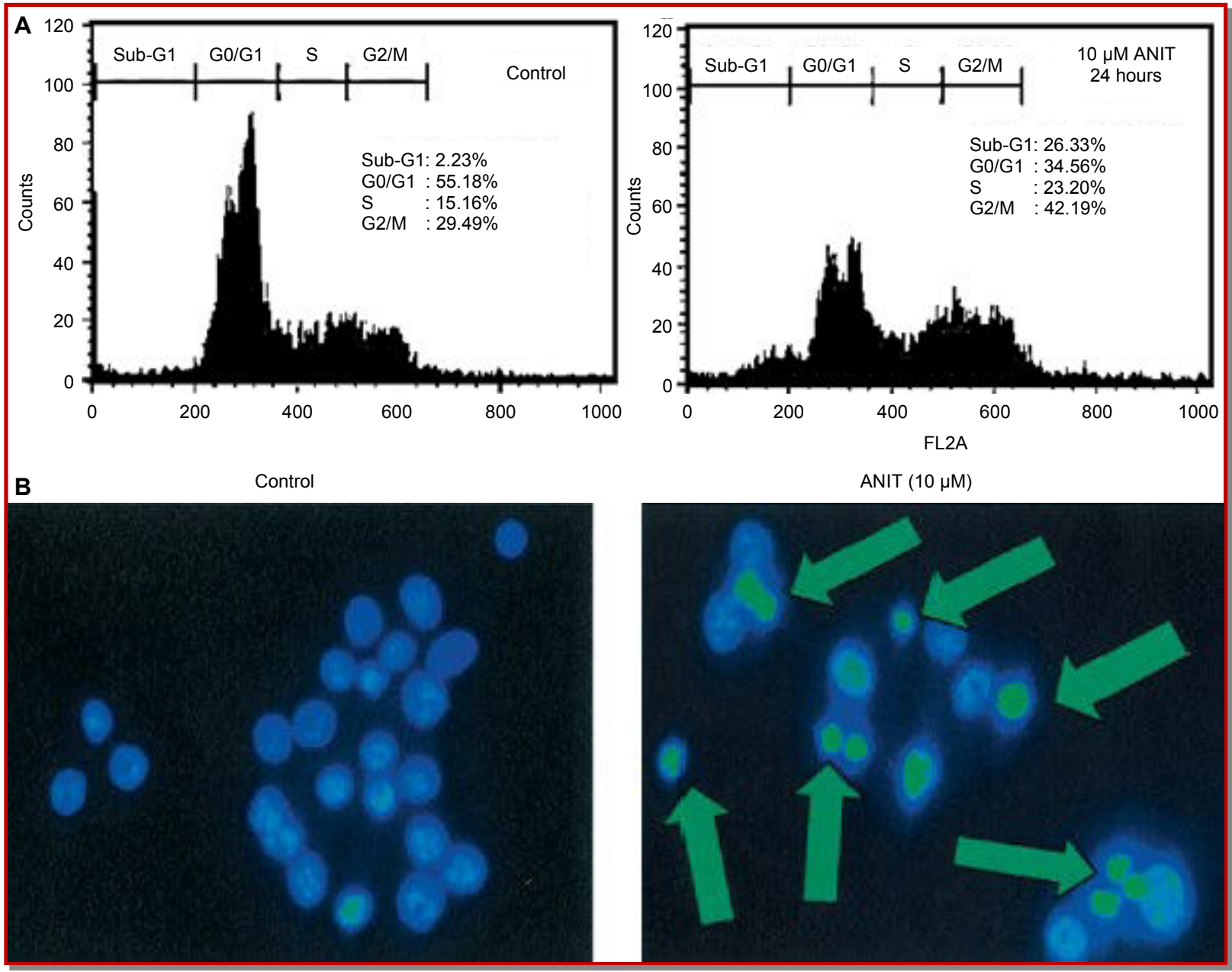

Figure 2: Effects of ANIT on cell cycle distribution (A) and chromatin condensation (B) in U87MG cells

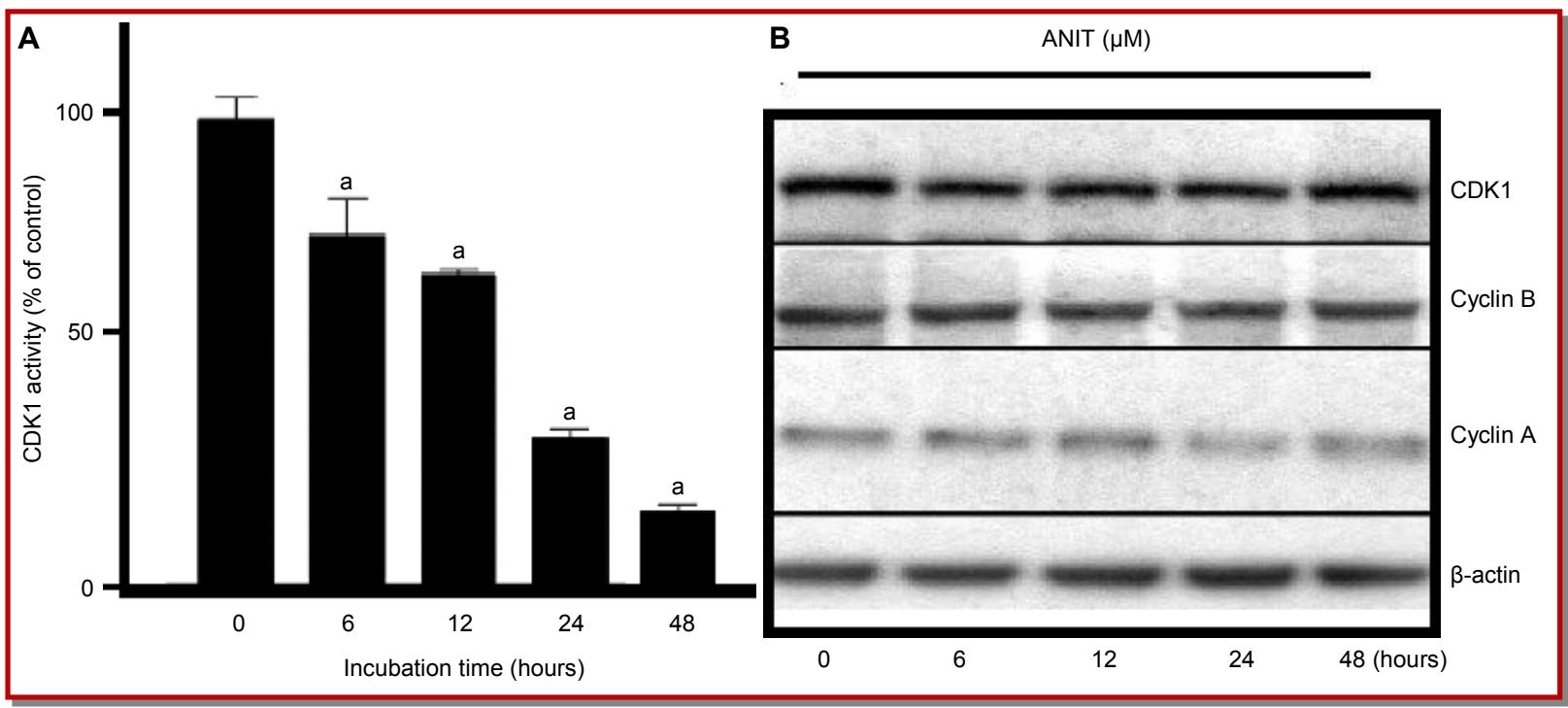

Figure 3: ANIT alters the levels of CDK1 activity (A), and the CDK1, cyclin (A) and cyclin (B) proteins of G2/M phase arrest in U87MG cells. Cells were incubated with $10 \mu \mathrm{M}$ AITC for $0,6,12$, and 24 hours for CDK1 activity 


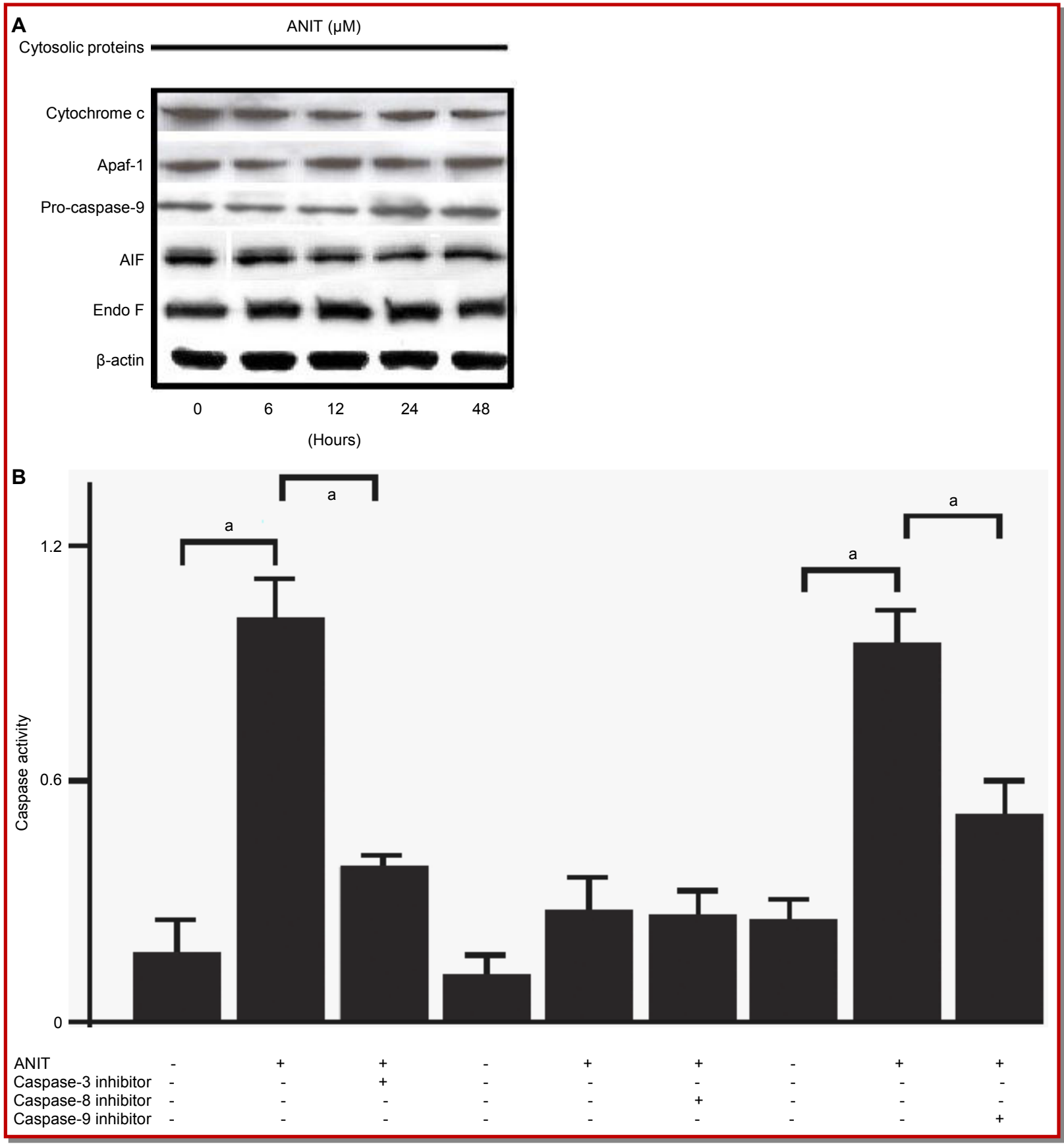

Figure 4: ANIT affects the relative protein levels of apoptosis (A) and caspase-3, -8 and -9 activities (B) in U87MG cells. ${ }^{a} \mathrm{p}<0.001$, significant difference

The $\mathrm{IC}_{50}$ of ANIT was $8.3 \pm 0.6 \mu \mathrm{M}$ after 24 hours treatment. In addition, the examined cells exhibited morphological changes, including rounding and shrinkage after 24 and 48 hours-incubation with 10 and $20 \mu \mathrm{M}$ of ANIT (Figure 1B). Viable cells were determined by MTT assay. The cell morphological changes were examined and photographed under phase-contrast microscopy (x200) as described in Materials and methods. There was a significant difference $\left({ }^{a} p<0.001\right)$ when compared with the control group by Student's t-test analysis.
Cells were treated with $10 \mu \mathrm{M}$ of AITC for 24 hours and then were analyzed and determined for cell cycle distribution by PI staining and flow cytometric analysis. AITC induced chromatin condensation (an apoptotic characteristic) in U87MG cells. Cells were incubated with $10 \mu \mathrm{M}$ of AITC for 24 hours and apoptotic cells were determined by DAPI staining and were photographed by fluorescence microscopy (x200) as described in Materials and Methods. ANIT induced reduction of cell viability could be due to apoptosis 


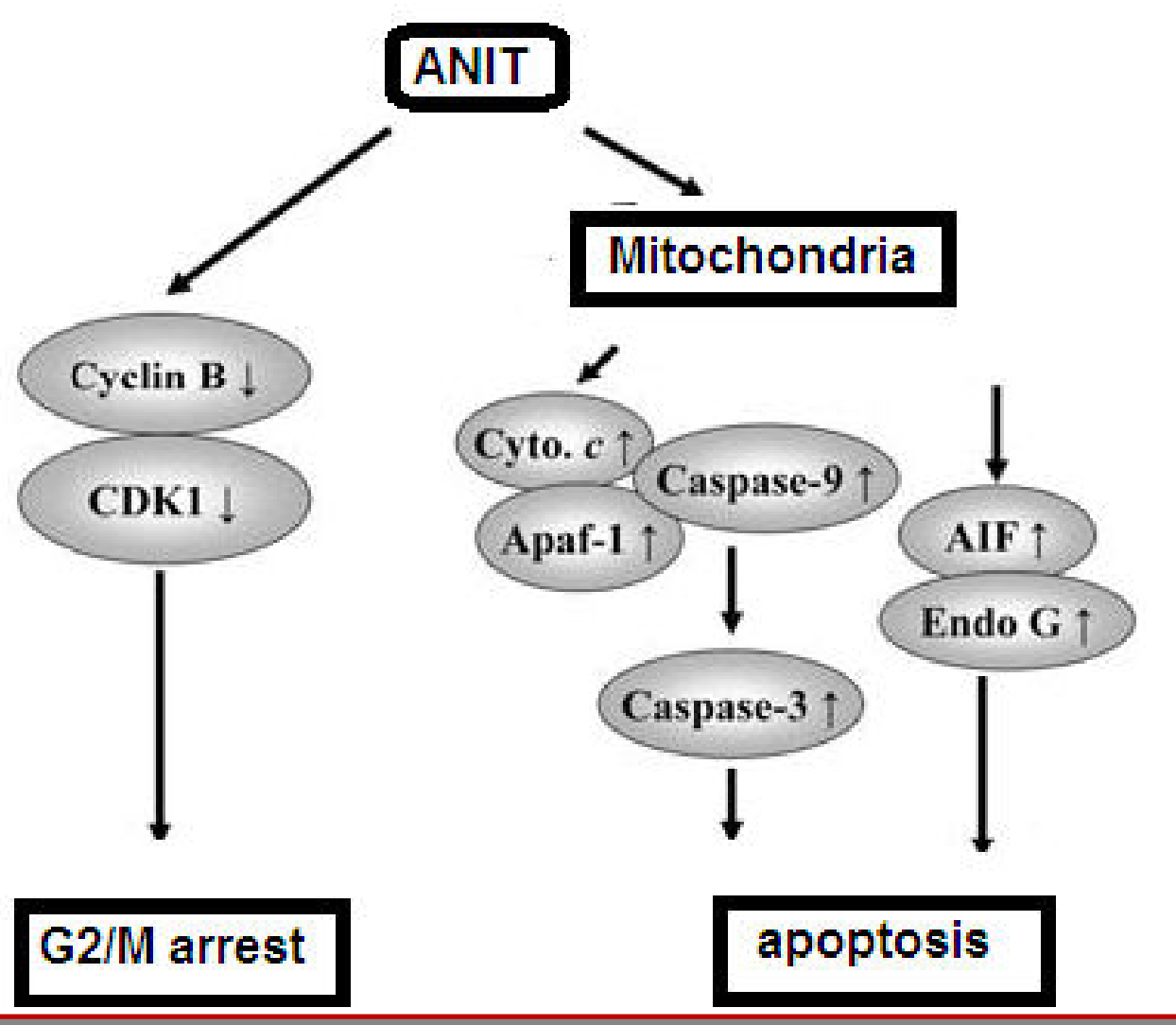

Figure 5: The proposed model of ANIT-induced G2/M phase arrest and apoptosis in U87MG cells

(sub-G1 population) mediated by cell cycle arrest which were determined. Representative profiles of cell cycle progression and percentage of each phase are presented in Figure 2A. Significant arrest was seen at G2/M phase at $10 \mu \mathrm{M}$ of ANIT and it significantly increased apoptotic cells (sub-G1groups) (Figure 2A). Apoptotic chromatistic (nuclear and chromatin condensation) in GBM8401 cells occurred with or without ANIT $(10 \mu \mathrm{M})$ treatment for 24 hours determined by DAPI staining (Figure 2B).

This experiment was carried out to prove ANITinduced accumulation of G2/M population in U87MG cells and it was regulated associated proteins. U87MG cells were incubated with $10 \mu \mathrm{M}$ AITC for $0,6,12,24$ and 48 hours, harvested from each sample and then relative protein levels were determined by Western blot analysis. The levels of CDK1, cyclin B and cyclin A were examined, and $B$-actin as an internal control using SDS-PAGE and Western blotting as described in Materials and Methods. ${ }^{a} \mathrm{p}<0.001$, was significantly different compared to the control group. The results are shown in Figure 3A and B. U87MG cells after exposure to AITC showed that a significant decrease of CDK1 activity (Figure 3A) and down-regulated the protein levels, including CDK1, cyclin B and cyclin A as shown in Figure 3B.
To assess the ANIT-induced apoptotic cell death, the results of Western blot analysis from $10 \mu \mathrm{M}$ of ANIT coincubation with U87MG cells for $0,6,12,24$ and 48 hours are shown in Figure 4A. The raise in protein levels of cytochrome C, Apaf-1, pro-caspase-9, AIF, and Endo $G$ in cytosolic fractions may contribute to the occurrence of ANIT-triggered mitochondrial apoptosis and this signaling was found to be time dependent. Figure $4 \mathrm{~B}$, showed that ANIT induced a significant rise in caspase- 3 and -9 activities rather than influence of caspase- 8 response. This stimulation of activity of the caspases cascade in U87MG cells was reduced after preincubation with specific inhibitors of caspase-3 and -9 , respectively. Based on these results, ANIT-induced cell death was correlated with caspase-dependent and independent mitochondrial apoptotic pathways.

\section{Discussion}

Isothiocyanates ITCs $(\mathrm{R}-\mathrm{N}=\mathrm{C}=\mathrm{S})$ are electrophilic compounds and are known to react predominantly with thiols, and to a much lesser extent with $\mathrm{NH}_{2}$ and $\mathrm{OH}$ groups (Drobinica et al., 1965; Brusewitz et al., 1977). Therefore, the major route of metabolism and elimination of ITCs from the body is the mercapturic acid pathway i.e. by formation of non-enzymatic and 
enzymatic conjugation with reduced glutathione (GSH) to give thiol conjugates. TCs was extensively studied in cancer cell lines originating from various tissues ( $\mathrm{Xu}$ et al., 2000; Srivastava et al., 2004). However, there is no report on ANIT in having anti-cancer activity against human brain malignant glioma.

The experimental results showed that ANIT induced cytotoxic responses in a dose dependent manner. It stimulated morphological changes such as rounding and shrinkage in U87MG cells after 24 and 48 hourstreatment. Cell growth and proliferation of mammalian and tumor cells occur through cell cycle progression. The inhibition of cell cycle distribution has been recognized as a target for anticancer agents (Schwartz et al., 2005; Kim et al., 2008). The results in the present study showed that U87MG cells when treated with 10 $\mu \mathrm{M}$ of ANIT for 24 hours resulted accumulation in the G2/M phase by flow cytometric analysis, suggesting the sequential events of cell cycle arrest followed by apoptosis. It is known that the CDK1/Cyclin B complex is one of the major regulators leading the G2/M progression or apoptosis. Hence, we investigated the U87MG cells after ANIT treatment determining the G2/ $\mathrm{M}$ phase regulated protein levels and the data showed that a decrease in the protein levels of CDK1, cyclin B and cyclin A by Western blot analysis, and CDK1 kinase assays revealed reduction of CDK1 activity at 6, 12 and 24 hours after $10 \mu \mathrm{M}$ of AITC treatment.

Apoptotic cell death induction is one of the best strategies for cancer treatment (Batista et al., 2009; Sanchez-Munoz et al., 2009). Our results indicated that ANIT induced apoptosis in U87MG cells. This was demonstrated by flow cytometric analysis and DAPI staining was applied to confirm cell apoptosis in examined U87MG cells. The results from the Western blot analysis showed that AITC increased protein levels of cytochrome C, Apaf-1, pro-caspase-9, AIF, and Endo $G$, suggesting that analyses of protein abundance indicated that AITC induced apoptosis through a mitochondria-dependent pathway. Also, AITC stimulates the loss of mitochondrial membrane potential resulting from the mitochondria dysfunction (data not shown). In this study, we observed the ANIT-induced caspase- 9 and -3 activities in U87MG and the specific inhibitors (Z-DEVEFMK for caspase-3 and Z-LEHDFMK for caspase-9) individually prevented ANITinduced caspase-3 and -9 activities, respectively in U87MG cells. ANIT-induced G2/M phase arrest and apoptosis in U87MG cells is shown in Figure 5.

In conclusion, we studied ANIT triggered G2/M phase arrest and apoptosis in U87MG cells. The experimental results showed that ANIT induced morphological changes on U87MG cells, decreased the percentage cell viability, increased $\mathrm{G} 2 / \mathrm{M}$ phase arrest, and stimulated the levels of caspase-9, -3, AIF and Endo G through a mitochondria dependent apoptotic pathway.

\section{References}

Batista LF, Kaina B, Meneghini R and Menck CF. How DNA lesions are turned into powerful killing structures: Insights from UV-induced apoptosis. Mutat Res. 2009; 681: 197-208.

Brusewitz G, Cameron BD, Chasseaud LF, Gorler K, Hawkins DR, Koch H, Mennicke WH. The metabolism of benzyl isothiocyanate and its cysteine conjugate. Biochem J. 1977; 162: 99-107.

Drobinica L, Augustine J. Reaction of isothiocyanate with amino acids, peptides and proteins. I. Kinetics of the reaction of aromatic isothiocyanates and glycines. Chem Commun. 1965; 30: 99-104.

Eitel K, Wagenknecht B, Weller M. Inhibition of drug-induced DNA fragmentation, but not cell death, of glioma cells by non-caspase protease inhibitors. Cancer Lett. 1999; 142: 1116.

Kim SJ, Min HY, Chung HJ, Park EJ, Hong JY, Kang YJ, Shin $\mathrm{DH}$, Jeong LS, Lee SK. Inhibition of cell proliferation through cell cycle arrest and apoptosis by thio-Cl-IB-MECA, a novel A3 adenosine receptor agonist, in human lung cancer cells. Cancer Lett. 2008; 264: 309-15.

Kuo HM, Tsai HC, Lin YL, Yang JS, Huang AC, Yang MD, Hsu SC, Chung MC, Gibson Wood W, Chung JG. Mitochondrialdependent caspase activation pathway is involved in baicalein-induced apoptosis in human hepatoma J5 cells. Int J Oncol. 2009; 35: 717-24.

Pawlik A, Szczepanski MA, Klimaszewska A, Gackowska L., Zuryn A., Grzanka A. Phenethylisothiocyanate-induced cytoskeletal changes and cell death in lung cancer cells. Food Chem Toxicol. 2012; 50: 3577-94.

Sanchez-Munoz A, Perez-Ruiz E, Mendiola Fernandez C, Alba Conejo E, Gonzalez-Martin A. Current status of antiangiogenic agents in the treatment of ovarian carcinoma. Clin Transl Oncol. 2009; 11: 589-95.

Schwartz GK, Shah MA. Targeting the cell cycle: A new approach to cancer therapy. J Clin Oncol. 2005; 23: 9408-21.

Singh SV, Kim SH, Sehrawat A, Arlotti JA, Hahm ER, Sakao K, Beumer JH, Jankowitz RC, Chandra-Kuntal K, Lee J. Biomarkers of phenethyl isothiocyanate-mediated mammary cancer chemoprevention in a clinically relevant mouse model. J Natl Cancer Inst. 2012; 104: 1228-39.

Srivastava SK, Singh SV. Cell cycle arrest, apoptosis induction and inhibition of nuclear factor kappa B activation in antiproliferative activity of benzyl isothiocyanate against human pancreatic cancer cells. Carcinogenesis 2004; 25: 1701 -09 .

Wattenberg LW. Inhibitory effect of benzyl isothiocyanates administered shortly before diethyl nitrosamine or benzo $(a)$ pyrene on pulmonary and fore stomach neoplasia in A/J 
mice. Carcinogenesis 1987; 12: 1971-73.

$\mathrm{Xu} \mathrm{K}$, Thornalley PJ. Studies on the mechanism of the inhibition of human leukemia cell growth by dietary isothiocyanates and their cysteine adducts in vitro. Biochem Pharmacol. 2000; 60: 221-31.

Yang JS, Chen GW, Hsia TC, Ho HC, Ho CC, Lin MW, Lin SS, Yeh RD, Ip SW, Lu HF, Chung JG. Diallyl disulfide induces apoptosis in human colon cancer cell line (COLO 205) through the induction of reactive oxygen species, endoplasmic reticulum stress, caspases casade and mitochondrial-dependent pathways. Food Chem Toxicol. 2009; 47: 171-79.

Yang JS, Hour MJ, Kuo SC, Huang LJ, Lee MR. Selective induction of G2/M arrest and apoptosis in HL-60 by a potent anticancer agent, HMJ-38. Anticancer Res. 2004; 24: 1769-78.

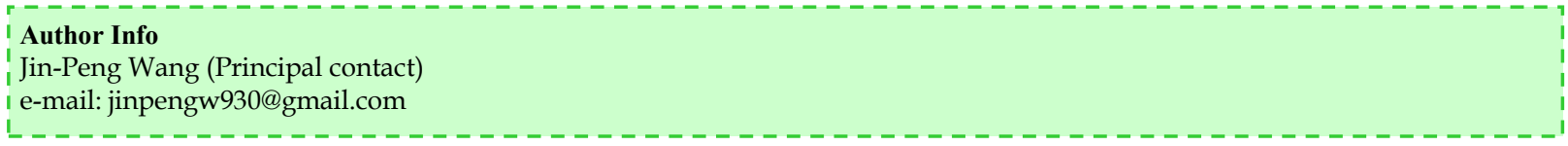




\section{Your feedback about this paper}

1. Number of times you have read this paper 0

2. Quality of paper Click

3. Your comments

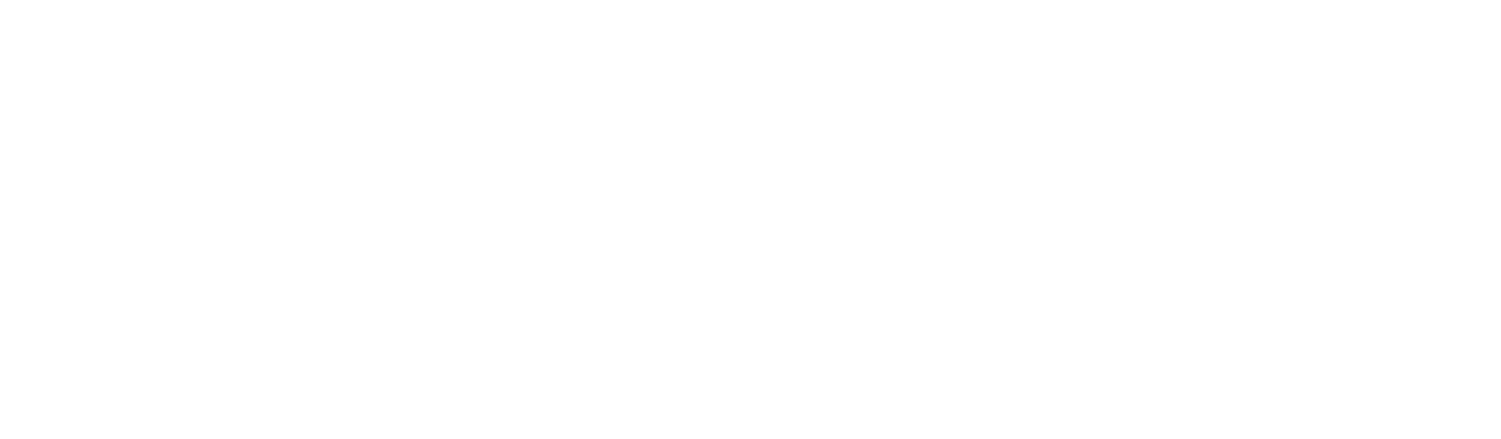

